\title{
Radon Awareness among Saudi People in Riyadh, Saudi Arabia
}

\author{
Abdulaziz S. Alaamer \\ Department of Physics, College of Science, Al-Imam Mohammad Ibn Saud Islamic University, Riyadh, KSA \\ Email: alaamer@hotmail.com
}

Received August 7, 2012; revised September 11, 2012; accepted September 21, 2012

\begin{abstract}
People should be aware of sources of health hazards, such as radon gas; and efforts should be made to educate them. Radon awareness among people is important for monitoring its level in their residential houses to reduce the risk of adverse health effects. Furthermore, radon awareness among public would support and facilitate researchers working for such surveys during the field work. In the present study, a public survey was conducted to investigate radon awareness level among Saudi people in Riyadh. A questionnaire was designed and distributed among 2297 persons of various educational background. It was found that about $82 \%$ of the Saudi public in Riyadh were ignorant of radon and its associated health risks. It was also found that only $~ 18 \%$ of educated public knew about radon. It was concluded that Saudi public needs to be educated in this respect properly.
\end{abstract}

Keywords: Radon; Awareness; Riyadh; Saudi Arabia

\section{Introduction}

Radon is a noble radioactive gas produced by decay of ${ }^{226} \mathrm{Ra}$, a member of ${ }^{238} \mathrm{U}$-decay series. Uranium is present in almost all types of rocks, soils, plants and ground waters. Radon $\left.{ }^{222} \mathrm{Rn}\right)$ is a significant indoor exposure source of natural background. Exposure to radon from soil, building materials or water may be through ingestion and/ or by inhalation of ${ }^{222} \mathrm{Rn}$ gas released from these sources, which pose potential health hazards [1-3]. In the last two decades, there has been a great deal of awareness about the health risks associated with radon and its decay products. ${ }^{222} \mathrm{Rn}$ and its progeny are one of the most significant natural sources of radiation exposure to the population [4]. Sustained exposure to indoor radon and its progeny is believed to be associated with a potential health risk of lung cancer [5]. The Surgeon General of the United States has assessed that radon is the second leading cause of lung cancer in the United States [6]. It is estimated that $50 \%-55 \%$ of the average annual dose from natural background radiation sources is contributed by ${ }^{222} \mathrm{Rn}[7]$.

Radon has been surveyed on a large-scale mainly in the USA and Europe [8-10]. The study of radon has been carried out in air, soils, building materials and water. Production rates from the soil depend upon the geological characteristics of the soil itself and its underlying geological strata [11]. The measurement of indoor radon levels have also been carried out in main cities of Saudi
Arabia [12-16].

Although radon gas level in Saudi Arabia is generally low [16,17], people should know the present levels of radon in their dwellings to avoid its health hazards. This present study gives results of a survey conducted in Riyadh city, the capital of Saudi Arabia regarding level of radon awareness among the general public. It is expected that this study will play an important role to educate Saudi people about radon and get them interested in assessing radon level in their houses. Furthermore, when uneducated Saudi people are aware of radon, they will not object the installation of radon do- simeters in their houses [18].

\section{Materials and Methods}

A questionnaire was designed containing questions relating to radon awareness among people in Riyadh of various educational backgrounds. The questionnaire was distributed randomly among university students, school teachers, government employees, municipality engineers, house contractors, real state offices and academics. Uneducated people were excluded from the questionnaire. Both genders, male and female participated in this survey. A total number of 2297 participants responded to the questionnaires. The questionnaire was divided into three sections as detailed below:

Section 1:

1) What is your qualification? [High Secondary School, Undergraduate, Graduate, Postgraduate] 
2) What is your study specialization? [Humanities, Medical, Scientific, Other]

3) Do you know Radon or have heard about it? [Yes, No]

Section 2:

4) What is Radon (1)? [Electronic device, Natural material, Artificial material, I don't know]

5) What is Radon (2)? [Gas, Liquid, Solid, I don't know]

6) Is Radon: [Active, Inactive, Radioactive, I don't know]

7) Is Radon: [Colorless, Odorless, Tasteless, I don’t know]

8) Where does Radon come from? [Underground, Water, Air, I don't know]

Section 3:

9) Is Radon harmful? [Yes, No, may be, I don't know]

10) Is Radon useful? [Yes, No, may be, I don't know]

11) If Radon is harmful or useful, where in body? [Head, Chest, Abdomen, I don't know]

\section{Results and Discussion}

Table 1 represents the results of survey conducted. It is shown that among the participants, $4.1 \%$ participants were high secondary school students, $30.2 \%$ college undergraduates, $64.6 \%$ college graduates, and $1.1 \%$ master and PhD holders. None of the school students had heard about radon at all. However, they were excluded from further analysis of the study. About $82.4 \%$ of participants had never heard about radon. Only $17.6 \%$ knew or had heard of radon. Those who had not heard about radon included undergraduates (91.2\%), graduates (77.7\%) and postgraduates $(53.8 \%)$. In general, almost all humanity-studied people (96.1\%) had not heard of radon. Only $3.9 \%$ people who had heard of radon among them were probably highly educated people. Obviously, about $50.7 \%$, $27.0 \%$ and $27.6 \%$ among specialists of science, medical and others, e.g., engineers respectively, had heard about radon.

The fourth question, which was "what is radon?", examined the truth and certainty of those who answered that they knew radon. Those who answered that radon was an electron device meant that they had not really heard about radon. About $95.5 \%$ participants from this section answered radon was a natural material as shown in Table 2. Section 2 of the questioner investigated the knowledge of radon characteristics as shown from Table 3. The majority of participants ( $\sim 97 \%)$ knew that radon is a radioactive, colorless, odorless, tasteless gas and underground material. Only $2.0 \%$ participants were unawared of radon. As reflected from Table 4, Section 3 of questioner investigated the awareness of health hazards of radon. Almost all participants ( 99\%) knew that radon is a harmful to the body.

Table 1. Survey results of the participants who knew or had heard of radon.

\begin{tabular}{|c|c|c|c|c|c|c|c|c|}
\hline & \multicolumn{2}{|c|}{ High S. School } & \multicolumn{2}{|c|}{ Undergraduate } & \multicolumn{2}{|c|}{ Graduate } & \multicolumn{2}{|c|}{ Postgraduate } \\
\hline What is your qualification? & \multicolumn{2}{|c|}{94} & \multicolumn{2}{|c|}{694} & \multicolumn{2}{|c|}{1483} & \multicolumn{2}{|c|}{26} \\
\hline \multirow[t]{5}{*}{$\%$ of total participants } & \multicolumn{2}{|c|}{$4.1 \%$} & \multicolumn{2}{|c|}{$30.2 \%$} & \multicolumn{2}{|c|}{$64.6 \%$} & \multicolumn{2}{|c|}{$1.1 \%$} \\
\hline & Yes & No & Yes & No & Yes & No & Yes & No \\
\hline & 0 & 94 & 61 & 633 & 331 & 1152 & 12 & 14 \\
\hline & $0.0 \%$ & $100.0 \%$ & $8.8 \%$ & $91.2 \%$ & $22.3 \%$ & $77.7 \%$ & $46.2 \%$ & $53.8 \%$ \\
\hline & \multicolumn{2}{|c|}{ Humanities } & \multicolumn{2}{|c|}{ Medical } & \multicolumn{2}{|c|}{ Scientific } & \multicolumn{2}{|c|}{ Other } \\
\hline Study specialization & \multicolumn{2}{|c|}{1421} & \multicolumn{2}{|c|}{37} & \multicolumn{2}{|c|}{546} & \multicolumn{2}{|c|}{199} \\
\hline \multirow[t]{4}{*}{$\%$ of total educated participants } & \multicolumn{2}{|c|}{$64.5 \%$} & \multicolumn{2}{|c|}{$1.7 \%$} & \multicolumn{2}{|c|}{$24.8 \%$} & \multicolumn{2}{|c|}{$9.0 \%$} \\
\hline & Yes & No & Yes & No & Yes & No & Yes & No \\
\hline & 56 & 1365 & 10 & 27 & 277 & 269 & 55 & 144 \\
\hline & $3.9 \%$ & $96.1 \%$ & $27.0 \%$ & $73.0 \%$ & $50.7 \%$ & $49.3 \%$ & $27.6 \%$ & $72.4 \%$ \\
\hline
\end{tabular}

Table 2. Testing whether participants truly had heard about radon.

\begin{tabular}{ccccc}
\hline Question & Electronic device & Natural material & Artificial material & I don't know \\
\hline What is radon (1) & 3 & 386 & 14 & 1 \\
\% of total participants & $0.4 \%$ & $16.8 \%$ & $0.6 \%$ & $0.0 \%$ \\
\% of total participants who know radon & $0.7 \%$ & $95.5 \%$ & $3.5 \%$ & $0.2 \%$ \\
\hline
\end{tabular}


Table 3. Awareness of radon characteristics.

\begin{tabular}{|c|c|c|c|c|}
\hline Question & Gas & Liquid & Solid & I don't know \\
\hline What is radon (2) & 385 & 6 & 5 & 8 \\
\hline$\%$ of total participants & $16.8 \%$ & $0.3 \%$ & $0.2 \%$ & $0.3 \%$ \\
\hline \multirow[t]{2}{*}{$\%$ of total participants who know radon } & $95.3 \%$ & $1.5 \%$ & $1.2 \%$ & $2.0 \%$ \\
\hline & Active & Inactive & Radioactive & I don't know \\
\hline Is radon & 1 & 0 & 392 & 11 \\
\hline$\%$ of total participants & $0.0 \%$ & $0.0 \%$ & $17.1 \%$ & $0.5 \%$ \\
\hline \multirow[t]{2}{*}{$\%$ of total participants who know radon } & $0.2 \%$ & $0.0 \%$ & $97.0 \%$ & $2.7 \%$ \\
\hline & Colorless & Odorless & Tasteless & I don't know \\
\hline Is radon & 392 & 392 & 392 & 7 \\
\hline$\%$ of total participants & $17.1 \%$ & $17.1 \%$ & $17.1 \%$ & $0.3 \%$ \\
\hline \multirow[t]{2}{*}{$\%$ of total participants who know radon } & $97.0 \%$ & $97.0 \%$ & $97.0 \%$ & $1.7 \%$ \\
\hline & Underground & Water & Air & I don't know \\
\hline Where does radon come from? & 400 & 255 & 311 & 0 \\
\hline$\%$ of total participants & $17.4 \%$ & $11.1 \%$ & $13.5 \%$ & $0.0 \%$ \\
\hline$\%$ of total participants who know radon & $99.0 \%$ & $63.1 \%$ & $77.0 \%$ & $0.0 \%$ \\
\hline
\end{tabular}

Table 4. Awareness of health hazards of radon.

\begin{tabular}{|c|c|c|c|c|}
\hline & Yes & No & May be & I don't know \\
\hline Is radon harmful? & 401 & 0 & 3 & 0 \\
\hline$\%$ of total participants & $17.5 \%$ & $0.0 \%$ & $0.1 \%$ & $0.0 \%$ \\
\hline \multirow[t]{2}{*}{$\%$ of total participants who know radon } & $99.3 \%$ & $0.0 \%$ & $0.7 \%$ & $0.0 \%$ \\
\hline & Yes & No & May be & I don't know \\
\hline Is radon useful? & 0 & 404 & 0 & 0 \\
\hline$\%$ of total participants & $0.0 \%$ & $17.6 \%$ & $0.0 \%$ & $0.0 \%$ \\
\hline \multirow[t]{2}{*}{$\%$ of total participants who know radon } & $0.0 \%$ & $100.0 \%$ & $0.0 \%$ & $0.0 \%$ \\
\hline & Head & Chest & Abdomen & I don't know \\
\hline If radon is harmful or useful, where in body? & 2 & 386 & 2 & 14 \\
\hline$\%$ of total participants & $0.1 \%$ & $16.8 \%$ & $0.1 \%$ & $0.6 \%$ \\
\hline$\%$ of total participants who know radon & $0.5 \%$ & $95.5 \%$ & $0.5 \%$ & $3.5 \%$ \\
\hline
\end{tabular}

From the above results it shows that in general, radon awareness increases among educated people with an increasing educational background level and with science education in particular. The radon awareness level among the general public in the USA is relatively higher than those of educated people in Saudi Arabia. Internet and other information media may be used to enhance radon awareness level. However, this survey showed that the radon awareness of general public is scarce. This suggests that efforts by the concern authorities should be made to improve radon awareness level via the press, media and lectures.

\section{Conclusion}

In general, Saudi people have poor radon awareness level. Among educated people, only $~ 18 \%$ are aware of radon and its health hazards. Radon awareness level increases among educated people with increasing scientific education level. Efforts should be made by the concern authorities to enhance radon awareness level in the general public using tools of the press, media and lectures. 


\section{REFERENCES}

[1] K. N. Yu, Z. J. Guan, M. J. Stokes and E. C. M. Young, "A Preliminary Study on the Radon Concentrations in Water in Hong Kong and the Associated Health Effects," Applied Radiation and Isotopes, Vol. 45, No. 7, 1994, pp. 809-810. doi:10.1016/0969-8043(94)90133-3

[2] M. J. Barnett, K. E. Holbert, B. D. Stewart and W. K. Hood, "Lung Dose Estimates from Radon in Arizona Ground Water Based on Liquid Scintillation Measurements," Health Physics, Vol. 68, No. 5, 1995, pp. 699703. doi:10.1097/00004032-199505000-00010

[3] Z. A. Tayyeb, A. R. Kinsara and S. M. Farid, "A Study on the Radon Concentration in Water in Jeddah and Associated Health Effects," Journal of Environmental Radioactivity, Vol. 38, No. 1, 1998, pp. 97-104. doi:10.1016/S0265-931X(97)00014-3

[4] S. Oikawa, N. Kanno, T. Sanada, N. Ohashi, M. Uesugi, K. Sato, J. Abukawa and H. Higuchi, "A Nationwide Survey of Outdoor Radon Concentration in Japan,” Journal of Environmental Radioactivity, Vol. 65, No. 2, 2003, pp. 203- 213. doi:10.1016/S0265-931X(02)00097-8

[5] M. Galan Lopez, A. Martin Sanchez and V. Gomez Escobar, "Estimates of the Dose Due to Radon-222 Concentrations in Water," Radiation Protection Dosimetry, Vol. 111, No. 1, 2004, pp. 3-7. doi:10.1093/rpd/nch350

[6] International Commission on Radiological Protection, "Protection against 222Rn at Home and at Work. International Commission on Radiological Protection Publication 65," Annals of the ICRP, Vol. 23, No. 2, 1993.

[7] United Nations Scientific Committee on the Effects of Atomic Radiation, "Sources and Effects of Ionizing Radiation," UNSCEAR Report to the General Assembly, New York, 1993.

[8] E. S. Ford, C. R. Eheman, P. Z. Siegal and P. L. Garbe, "Radon Awareness and Testing Behavior: Findings from the Behavioral Risk Factor Surveillance System, 19891992,” Health Physics, Vol. 70, No. 3, 1996, pp. 363-366. doi:10.1097/00004032-199603000-00006

[9] Y. Wang, C. Ju, A. D. Stark and N. Teresi, "Radon Awareness, Testing, and Remediation Survey among New York State Residents," Health Physics, Vol. 78, No. 6, 2000, pp. 641-647.

\section{doi:10.1097/00004032-200006000-00006}

[10] B. Gregory and P. P. Jalbert, “National Radon Results: 1985 to 2003,” US Environmental Protection Agency, Washington DC, 2003,

[11] B. Lévesque, D. Gauvin, R. G. McGregor, R. Martel, S. Gingras, A. Dontigny, W. B. Walker, P. Lajoie and E. Letourneau, "Radon in Residences: Influences of Geological and Housing Characteristics," Health Physics, Vol. 72, No. 6, 1997, pp. 907-914.

[12] F. Abu-Jarad and M. I. Al-Jarallah, "Radon Activity in Saudi Houses,” Radiation Protection Dosimetry, Vol. 14, 1986, pp. 243-249.

[13] F. Abu-Jarad, M. I. Fazal-ur-Rehman, Al-Jarallah and A. Al-Shukri, "Indoor Radon Survey in Dwellings of Nine Cities of the Eastern and the Western Provinces of Saudi Arabia,” Radiation Protection Dosimetry, Vol. 106, No. 3, 2003, pp. 227-232. doi:10.1093/oxfordjournals.rpd.a006353

[14] M. S. Garawi, "Measurement of Radon Concentration in Private Houses in the Eastern Part of AL-Qaseem Province of Saudi Arabia," Radiation Protection Dosimetry, Vol. 63, No. 3, 1996, pp. 227-230. doi:10.1093/oxfordjournals.rpd.a031534

[15] M. I. Al-Jarallah and Fazal-ur-Rehman, "Indoor Radon Concentration Measurement in the Dwellings of Al-Jauf Region of Saudi Arabia,” Radiation Protection Dosimetry, Vol. 121, No. 3, 2006, pp. 293-296. doi:10.1093/rpd/ncl023

[16] F. S. Al-Saleh, K. A. Zarie, K. Al-Magran and M.S. Sharaf, "Measurements of Radon Concentration and Exhalation Rate from Some Construction Materials Used in Riyadh Region (KSA)," Isotopes and Radiation Research, Vol. 33, 2001, pp. 261-265.

[17] F. S. Al-Saleh, "Measurements of Indoor Gamma Radiation and Radon Concentrations in Dwellings of Riyadh City, Saudi Arabia,” Applied Radiation and Isotopes, Vol. 65, No. 7, 2007, pp. 843-848. doi:10.1016/j.apradiso.2007.01.021

[18] S. Rahman, M. Faheem, S. Rehman and Matiullah, "Radon Awareness in Pakistan," Radiation Protection Dosimetry, Vol. 121, No. 3, 2006, pp. 333-336. doi:10.1093/rpd/ncl021 